\title{
La traction cameline, un apport important dans l'évolution des pratiques de traction animale au Niger
}

\author{
S.G. Vias Franck ${ }^{1}$ E. Vall ${ }^{2}$ Y. Ibrahim ${ }^{1}$ B. Faye ${ }^{2}$
}

Mots-clés

Camelus dromedarius - Energie animale - Ingénierie - Matériel Niger.

\section{Résumé}

L'utilisation du dromadaire pour la culture attelée et le transport au moyen de la charrette a été une évolution des pratiques de traction animale observée en zone agricole subsaharienne. Le dromadaire représente le stade ultime de I'intensification agricole. Son utilisation pour la traction a été promue car elle répond à la demande d'un développement durable adapté aux ressources disponibles au Niger. Cette communication présente les outils à traction cameline mis au point par le projet de Renforcement institutionnel et technique de la filière cameline, les spécifications techniques de chaque matériel fabriqué, et la stratégie adoptée pour vulgariser la traction cameline au Niger.

\section{INTRODUCTION}

La traction animale est apparue très tôt au Niger comme un facteur de modernisation de l'agriculture nationale (4). Diverses stratégies ont été développées pour assurer sa diffusion : création de coopératives agricoles, formation de paysans et d'artisans, octroi de crédits agricoles, vulgarisation de la traction bovine et asine. Ces deux espèces ont été ciblées pour promouvoir l'énergie animale au Niger. Après quatre décennies de diffusion massive, une dynamique nouvelle émerge de certaines exploitations agricoles, liée à l'usage du dromadaire pour le travail agricole: scarifiage, labour, semis et sarclage. Cette nouvelle dynamique se justifie par l'avantage comparatif de cette espèce. En effet, le dromadaire est doté d'une capacité de traction supérieure aux autres animaux domestiques et se montre notamment plus puissant, plus rapide et plus résistant qu'une paire de bœufs (5).

\footnotetext{
1. Cellule d'appui à la promotion de l'élevage au Niger, BP 510, Niamey, Niger E-mail : camelin@intnet.ne

2. Cirad, département Emvt, TA30/A, campus international de Baillarguet, 34398 Montpellier Cedex 5, France

E-mail : faye@cirad.fr
}

Cette communication présente les outils à traction cameline mis au point par le projet de Renforcement institutionnel et technique de la filière cameline (dénommé Projet ci-après), les spécifications techniques de chaque matériel fabriqué, et la stratégie adoptée pour vulgariser la traction cameline au Niger.

\section{MISE AU POINT D'OUTILS} ET SPECIFICATIONS TECHNIQUES DES MATERIELS FABRIQUES

La traction cameline semble la plus performante pour intensifier le travail agricole avec l'animal (2), mais son développement est limité au Niger par la méconnaissance et le manque de savoir-faire. Le projet filière cameline s'est donc donné pour objectif de mettre au point, tester et diffuser auprès des structures d'encadrement des outils de traction attelée cameline.

\section{Charrette cameline}

Deux prototypes de charrette agricole ont été construits et mis à l'essai en milieu paysan. Des améliorations ont permis d'aboutir à un modèle standard dérivé de la charrette bovine classiquement 
fabriquée au Niger ; elle est destinée aux paysans (figure 1). Un tombereau, dérivé de la charrette avec un plateau métallique pivotant, a été mis au point pour répondre aux besoins de transport de matériaux lourds : fumier, ordures ménagères, sable, pierres (figure 2).

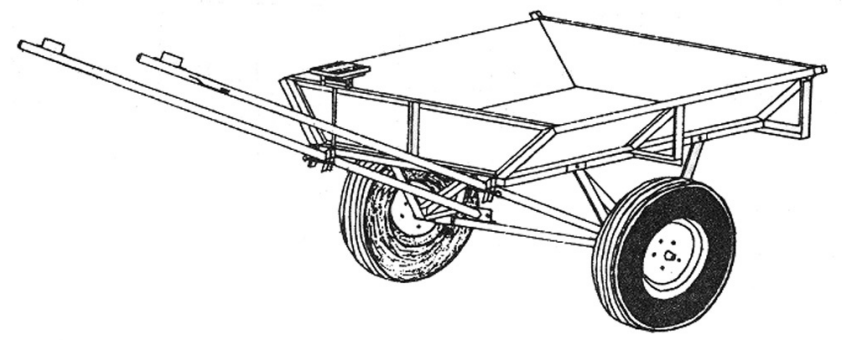

Figure 2 : tombereau à traction cameline.

\section{Culture attelée}

Des harnachements pour l'exhaure, la culture attelée et la traction de charrette ont été mis au point. La selle pour la charrette et le tombereau camelin sont composés de deux figures en bois de $0,40 \mathrm{~m}$ x $0,15 \mathrm{~m}$ réunies par deux arceaux en fer plat de 40/4. Deux barres métalliques longitudinales en fer plat de 35/4 relient les deux arceaux et portent en avant un crochet en U (largeur $5 \mathrm{~cm}$ ), soudé vers le haut, qui permet de caler la chaîne de la charrette et du tombereau. Une fine tôle métallique de $10 / 10^{\mathrm{e}}$ recouvre les figures sur $15 \mathrm{~cm}$ de large vis-à-vis des fers en U. Deux capitons en tissu sont placés sous les figures pour limiter les plaies de selles. Deux solides crochets en fer de $5 \mathrm{~cm}$ de diamètre sont fixés à l'arrière et à l'avant de chaque figure. Une épaisse matelassure est placée sous la selle. Une bricole en cuir de $2 \mathrm{~cm}$ d'épaisseur, large aux extrémités $(20 \mathrm{~cm})$ et légèrement rétrécie en son milieu $(17 \mathrm{~cm}$ de large) reste solidaire de la selle. Une corde en cuir se détache de la partie supérieure, au milieu de la bricole. Deux crochets sont fixés de part et d'autre de la bricole. L'angle d'insertion des crochets est de $45^{\circ}$ (figure 3).

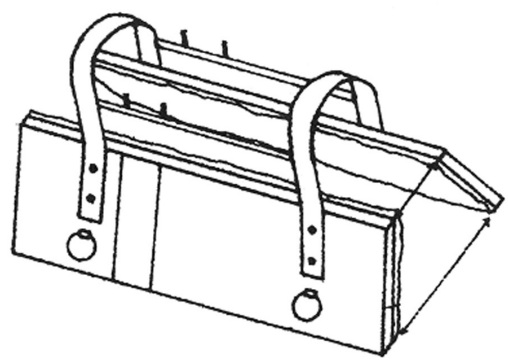

Figure 3 : selle à traction cameline pour la culture attelée.
ACTION DE PROMOTION DE LA FILIERE CAMELINE

Après avoir mis au point les outils à traction cameline, le Projet s'est lancé, auprès des projets de développement, et des populations d'éleveurs et de paysans nigériens, dans la promotion des différents matériels novateurs, et ce, sur deux niveaux : i) par l'élaboration de manuels techniques de vulgarisation pour servir de support de sensibilisation et de diffusion des connaissances, ii) par une campagne de sensibilisation des structures de développement agricole.

\section{Elaboration de manuels de références techniques}

Les deux guides techniques présentés ci-après sont disponibles en ligne sur le site http://cirad.camelides.fr.

\section{Guide de bonne utilisation du dromadaire comme force animale}

Ce guide présente de façon synthétique les connaissances nécessaires et suffisantes pour utiliser de façon optimale les différentes techniques pour le bât, l'exhaure, la culture attelée et la traction de charrettes. Des chapitres traitent du matériel, des performances de travail, du dressage, des soins, de l'entretien de l'animal... Le guide est illustré pour être accessible aux paysans. Une formation initiale est dispensée par le Projet afin que ce guide constitue le support technique d'un module de vulgarisation dispensé aux paysans par les agents de terrain.

\section{Manuel de traitement des maladies du dromadaire}

Un guide de vulgarisation a été conçu pour former les paysans et auxiliaires d'élevage au traitement des maladies des dromadaires qui constituent, après l'alimentation, la seconde contrainte à la productivité de l'élevage camelin au Niger et à l'utilisation de la force du dromadaire. Ce guide pratique donne, sous forme de textes courts et de dessins, les éléments nécessaires et suffisants pour identifier, traiter et parfois prévenir les maladies camelines rencontrées au Niger et dans le Sahel.

\section{Sensibilisation des structures de développement agricole}

Après l'élaboration des manuels techniques, les structures de développement agricole ont été sensibilisées par le Projet aux atouts présentés par la traction cameline et les bénéfices à en tirer par les paysans. Finalement, ces structures deviennent les promoteurs du développement de la traction cameline au Niger en assurant : i) la formation des agents de vulgarisation et des paysans à la traction cameline, ii) le suivi et l'encadrement des paysans sur le terrain, iii) un crédit à l'équipement d'unités de culture attelée cameline.

\section{CONCLUSION}

Le frein majeur au développement au Niger de la promotion de la charrette cameline est lié, d'une part, à la méconnaissance des techniques (matériels, performances, avantages par rapport aux autres espèces animales) et, d'autre part, à celle de l'animal (élevage, dressage, alimentation et encadrement sanitaire), notamment dans la population sédentaire du sud du pays où les potentialités de développement sont les plus grandes. Si la culture attelée cameline tend à se développer depuis une dizaine d'année, la traction de charrettes se développe difficilement dans un contexte où tous les éléments nécessaires à son lancement sont présents : existence d'une activité de transport importante (récoltes, bois, briques, fumier, personnes...), présence de dromadaires dans tout le pays, couverture du territoire par de nombreux projets de développement pouvant subventionner l'achat d'un nouveau type de charrette ou octroyer des crédits à l'équipement, et réseau important de forgerons soudeurs. 
1. BORDET D., LHOSTE P., LE MOIGNE M., LE THIEC G., 1988. La traction animale en Afrique francophone. Etat de l'art. Antony, France, Cirad-Ceemat, 195 p.

2. FAYE B., 1997. Guide de l'élevage du dromadaire. Libourne, France, Sanofi, 126 p.
3. PACHOLEK X., 1996. Situation de l'élevage camelin au Niger. Niamey, Niger, ministère de l'Agriculture et de l'Elevage, 7 p.

4. PEARSON R.A., LAWRENCE P.R., JANSEN H.G.P., 1990. Animal traction in Niger: prospects for the future. Niamey, Niger, ILCA, ICRISAT Sahelian Center, 63 p.

5. VALL E., 1996. Capacités de travail, comportement à l'effort et réponses physiologiques du zébu, de l'âne et du cheval au NordCameroun. Thèse Doct., Ensam, Montpellier, France, 418 p.

\section{Summary}

Vias Franck S.G., Vall E., Ibrahim Y., Faye B. Draft Camel Power, a Major Contribution to the Development of Draft Animal Practices in Niger

Camel use for draft and carting was developed out of draft practices observed in rural zones of Subsaharan Africa. The camel represents the ultimate stage of rural intensification. Its use was promoted because it is an answer to sustainable development adapted to available resources in Niger. The present communication presents the tools for camel draft developed by the project 'Technical and institutional strengthening of the camel subsector'. Then are described technical specifications for each draft material. Finally, the strategy adopted to popularize draft camel power is presented.

Keywords: Camelus dromedarius - Animal power - Engineering - Material - Niger.

\section{Resumen}

Vias Franck S.G., Vall E., Ibrahim Y., Faye B. La tracción por dromedario, un aporte importante para la evolución de las prácticas de tracción animal en Níger

El uso del dromedario para el cultivo con atelaje y el transporte mediante la carreta a constituido una evolución de las prácticas de tracción animal observada en la zona agrícola sub sahariana. El dromedario representa el último estadio de la intensificación agrícola. Su uso para la tracción con dromedarios a sido promovido puesto que corresponde a la demanda de un desarrollo durable adaptado a los recursos disponibles en Níger. Esta comunicación presenta los instrumentos para una tracción por dromedarios, establecidos por el proyecto de Refuerzo institucional y técnico de la filiar de camélidos, describe luego las especificaciones técnicas de cada material fabricado. Finalmente, se presenta la estrategia adoptada para divulgar la tracción por dromedarios en Níger.

Palabras clave: Camelus dromedarius - Animal de tiro - Ingeniería - Equipo - Níger. 